\title{
Developing and solving two-echelon inventory system for perishable items in a supply chain: case study (Mashhad Behrouz Company)
}

\author{
Mirbahador Gholi AriaNezhad', Ahmad Makuie ${ }^{2}$ and Saeed Khayatmoghadam ${ }^{3 *}$
}

\begin{abstract}
In this research, a new two-echelon model has been presented to control the inventory of perishable goods. The performance of the model lies in a supply chain and is based on real conditions and data. The main purpose of the model is to minimize the maintenance cost of the entire chain. However, if the good is perished before reaching the customer (the expiration date is over), the cost would be added to other costs such as transportation, production, and maintenance costs in the target function. As real conditions are required, some limitations such as production time, storage capacity, inventory level, transportation methods, and sustainability time are considered in the model. Also, due to the complexity of the model, the solution approach is based on genetic algorithm under MATLAB to solve and confirm the accuracy of the model's performance. As can be noted, the manipulation of parametric figures can solve the problem of reaching the optimum point. Using real data from a food production facility, the model was utilized with the same approach and the obtained results confirm the accuracy of the model.
\end{abstract}

Keywords: Two-echelon inventory control; Genetic algorithm; Supply chain; Perishable good

\section{Introduction}

Most manufacturing systems inevitably maintain some quantities of their products under their inventories in order to respond to customers' needs appropriately and to prevent extra costs. Thus, inventory control and maintenance is a common problem for most factories, especially for those organizations that are involved in a supply chain.

There are many differences among inventory control and maintenance systems due to quantity and complexity of items, type and nature of items, costs of operating system, multi-echelonment of system, probability degree of system, and even competitors status. It is obvious that all existing cases should be considered to plan an inventory control system properly.

This study intends to present a model for managing short-lived products requiring a two-echelon inventory control. In the following section, we are presenting some

\footnotetext{
* Correspondence: skhayatmoghadam@gmail.com

${ }^{3}$ Dep. Of Management, Mashhad Branch, Islamic Azad University, Mashhad, Iran Full list of author information is available at the end of the article
}

of the more significant and recent studies that have been done in this aspect.

\section{Background studies}

Kyung and Dae (1989) have offered an innovative approach for the probable inventory control model in a way that a two-echelon distribution system has a central warehouse and stores items in the local warehouses for distribution. The offered algorithm was a step-by-step algorithm designed to obtain the optimum or nearly optimum result and also to minimize the sum of system cost variables in a year.

Have investigated an economic ordering policy for the deterministic two-echelon distribution systems. In this article, an algorithm is recommended to determine the economic ordering policy in order to provide producer's items centrally and distribute these items from the central warehouse to some local warehouses. Also, the products are to be distributed to customers through local warehouses. In this case, the purpose is to minimize the producers' overall costs that are results of order costs, distribution costs, and related inventory 
shipment costs to central and local warehouses. Dada (1992) has analyzed the two-echelon system for spare parts. This system allows a rapid dispatch at the time of inventory shortage.

Bookbinder and Chen (1992) have studied the twoechelon inventory system based on a multi-criterion point of view. The definition of the developed model was dealt with, specifying the optimum quantity of economic ordering in the central and local warehouses; it designed and resolved a two-criterion system to minimize the related costs of inventory system and displacement systems.

Shtub and Simon (1994) have discussed about the determination of order points in the two-echelon inventory system of spare parts. This system includes a central warehouse in which all service centers are supported. Each service center meets a random demand. The related costs of inventory transferred to both echelons are identical, but the probability of shortage occurrence among several maintenance service centers is different. The inventory management policy specifies the amount of order point for each service center.

Bertrand and Bookbinder (1998) have assessed the two-echelon system with the possibility of redistribution. They developed an algorithm to perform this redistribution. In this study, the developed model has been evaluated.

In another research, Miner (2005) has designed an inventory control model with several suppliers. At the same year, a mathematical model was designed in order to reduce warehouse-kept quantity by lowering the purchase batch.

Moon et al. (2005) have expanded the model of economic ordering quantity for perishable and improvable goods by considering the time value of money. Yang and Wee 2002 have presented a model for the integrated planning of production and inventory of perishable goods; this model allocated to study a single product status and a system that consisted of one producer and a few retailers. This model was introduced supposing the limited production rate, the demand without waiting time, and the integrated production and inventory for perishable goods (Moon et al. 2005). Rau et al. (2003) extended a multi-echelon model among suppliers, producers, and customers for perishable goods in a way that a numerical example has shown that after specifying the overall cost function, the integration approach in comparison with decision making resulted in the reduction of overall cost. Chen and Lee (2004) proposed the multi-objective synchronized optimization opposite to indefinite prices. They were the first researchers who raised multi-objective optimization in supply chain networks.
Based on the supply chain approach and considering the required service levels, Hwang (2002) has designed a logistic system that includes some manufacturing centers, warehouses or distribution center, and customers with indefinite demands in which distances are distributed randomly. In order to solve this problem, initially, random overall coverage was used to establish warehouses, and the objective function was stated to minimize the logistic costs and the number of warehouses which can be established. To decide about finding directions and specifying the ordering quantity of warehouses to production centers, an object-oriented planning approach based on genetic algorithm had been taken so that the total logistic costs could be minimized. In this case, all demands should be satisfied; however, there are some limitations on travel time, capacity, speed, type, and number of transportation means (Hwang 2002).

Bollapragada et al. (1998) surveyed the distribution system including one depot and some warehouses. In this system, the demand is created at random and at warehouse level, and the process is as follows: at the beginning of every depot, the order is presented to a supplier who is not from the system, and this order will be received by a depot after a fixed waiting time. The depot will then forward the received orders to the warehouses. The fixed waiting time was considered between the depot and the warehouses, and the shortage was supposed as the delayed orders; the warehouses have been evaluated at random.

Erenguc et al. (1999) have investigated on inventory decisions in the supply chain and they proposed a mathematical model based on the following assumptions including: the delayed orders are not allowed. Waiting times among factories and the distribution centers as well as waiting times among the distribution centers and customers are zero. In this model, each distribution center decides about inventory, and each customer focuses on determining the order quantities in order to balance between maintenance and ordering costs.

Hoque and Goyal (2000) have studied on specifying optimization policies for the integrated system of production and inventory, which comprised a single buyer and single vendor, and have considered the following assumptions in developing this model: First, the demand rate is definite and fixed. Second, the total accumulative production can be transferred to identical or different batches, but in any case, the fixed cost will be calculated for each dispatch. Third, shortage is not allowed, and transportation time is too slight, so it will not be accounted. Also, all values were supposed fixed and definite. Finally, the time horizon under this study has been regarded indefinite. The particular feature of this model is that it is studied under the condition of the limited capacity of transportation means. 
Zhou and Min (2002) have designed a supply chain network which balanced the transportation cost and service level in the best manner in which the working load given to all distribution centers are identical. Accordingly, this caused the decrease of shortage in warehouse inventories, the postponed orders, and the delay in responding to the customers' needs; at the same time, the loading and usage rates of distribution centers are increased. For this aim, they considered an objective function to minimize the maximum transportation distance related to distribution centers and used the formula of balanced star comprehensive tree; finally, they used the genetic algorithm for solving.

\section{Clarifying the research question}

In this research, a two-echelon warehousing system was observed for short-lived goods. Following the required surveys and in view of different limitations covering the research question, a program was written on MATLAB environment, and the genetic algorithm based on the written program was used for testing the accuracy of the presented model as well for solving the model in order to obtain the required values that can be noticed in the objective function which is minimizing the costs. In addition, as this research was done based on a real situation, after the model was analyzed, this model was resolved based on real numbers, in which the related result also was obtained, and solved using the genetic algorithm. The obtained results have been confirmed and used by related factories. The presented model includes the following assumptions:

1. The system has one producer and several consumers. Products are produced in the original factory and then transferred to the given warehouses of other factories (this means a two-echelon nature).

2. This model has been considered for different transportation capacities (truck, trailer, etc.).

\section{Table 1 Decisions and variables}

\begin{tabular}{ll}
\hline Variable & Definition of decision \\
\hline$X_{k L m}^{t}$ & $\begin{array}{l}\text { The quantity of goods } L \text { which were transferred from the } \\
\text { original factory to the factory } k \text { via transportation model } m \text { in } \\
\text { a period } t\end{array}$ \\
$\mathrm{PZ}^{t} \quad \begin{array}{l}\text { This denotes whether the original factory was active in period } \\
t \text { or not (variables of } 0 \text { and } 1 \text { ) }\end{array}$ \\
$B_{k L}^{t} \quad \begin{array}{l}\text { Accumulative quantity of delayed demand of goods } L \text { till the } \\
\text { period } t \text { in the applicant factory } k\end{array}$ \\
$\ln _{k L}^{t} \quad \begin{array}{l}\text { Accumulative quantity of goods inventory } L \text { till the period } t \\
\text { in the applicant factory } k\end{array}$ \\
$V_{k L}^{t} \quad \begin{array}{l}\text { This denotes the delay or maintenance of goods } L \text { till the } \\
\text { period } t \text { in the applicant factory } k \text { (variables of } 0 \text { and } 1)\end{array}$ \\
\hline
\end{tabular}

Table 2 Parameters and variables

\begin{tabular}{|c|c|}
\hline Variable & Definition of parameters \\
\hline$P C_{k L m}^{t}$ & $\begin{array}{l}\text { Transportation cost for each unit of goods } L \text { from the original } \\
\text { factory to factory } k \text { through the model } m \text { in the period } t\end{array}$ \\
\hline $\mathrm{PF}^{t}$ & Fixed cost of the original factory in the period $t$ \\
\hline $\mathrm{Pb}_{L}^{t}$ & $\begin{array}{l}\text { Production cost of goods } L \text { in the original factory in the } \\
\text { period } t\end{array}$ \\
\hline $\mathrm{dh}_{L}^{t}$ & $\begin{array}{l}\text { Maintenance cost for each unit of goods } L \text { in the original } \\
\text { factory in the period } t\end{array}$ \\
\hline $\mathrm{dk}_{L}^{t}$ & Demand of product $L$ by the factory $k$ in the period $t$ \\
\hline $\mathrm{ps}_{L}^{t}$ & $\begin{array}{l}\text { Required time for production of each unit of goods } L \text { in the } \\
\text { original factory in the period } t\end{array}$ \\
\hline $\mathrm{pu}^{t}$ & $\begin{array}{l}\text { Total production time which is available for the original } \\
\text { factory in the period } t\end{array}$ \\
\hline $\mathrm{Du}^{t}$ & $\begin{array}{l}\text { Total maintenance capacity of warehouse in the original } \\
\text { factory in the period } t\end{array}$ \\
\hline $\mathrm{PV}_{L}^{t}$ & Quantity (volume) of each unit of goods $L$ in the period $t$ \\
\hline $\mathrm{PV}_{m}^{t}$ & $\begin{array}{l}\text { Total volume capacity of forwarded goods based on the } \\
\text { transportation model } m \text { from the original factory in the period } t\end{array}$ \\
\hline $\mathrm{bl}_{k}^{t}$ & $\begin{array}{l}\text { Maximum delayed order of product } L \text { in the original factory } \\
\text { in the period } t\end{array}$ \\
\hline$\pi_{k L}^{t}$ & $\begin{array}{l}\text { Cost coefficient related to daily penalty of early delivery of } \\
\text { goods } L \text { in the factory } k \text { in the period } t \text { (earlier delivery than } \\
\text { due time) }\end{array}$ \\
\hline$\delta_{k L}^{t}$ & $\begin{array}{l}\text { Cost coefficient related to daily penalty of delay delivery of } \\
\text { goods } L \text { in the factory } k \text { in the period } t\end{array}$ \\
\hline W & Cost of each unit of perished goods \\
\hline$E X_{L}$ & Consumption date of the goods $L$ (month) \\
\hline$Q_{K L}^{t}$ & Maintenance capacity of product (goods) $L$ in the factory $k$ \\
\hline
\end{tabular}

Table 3 Variable and corresponding $L_{1}$ and $L_{2}$

\begin{tabular}{|c|c|c|}
\hline Variable & $L_{1}$ & $L_{2}$ \\
\hline$P C_{k L m}^{t}$ & 6,000 Rial (for each unit) & 6,000 Rial (for each unit) \\
\hline $\mathrm{PF}^{t}$ & 20,000,000 Rial & 20,000,000 Rial \\
\hline $\mathrm{Pb}_{L}^{t}$ & 300,000 Rial & 300,000 Rial \\
\hline $\mathrm{dh}_{L}^{t}$ & 100 Rial & 100 Rial \\
\hline $\mathrm{dk}_{L}^{t}$ & 150 units & 150 Unit \\
\hline $\mathrm{ps}_{L}^{t}$ & $1 / 12,500$ & $1 / 6,250$ \\
\hline $\mathrm{pu}^{t}$ & $0.5 t$ & $0.5 t$ \\
\hline $\mathrm{Du}^{t}$ & $8,000 \mathrm{~m}^{2}$ & $8,000 \mathrm{~m}^{2}$ \\
\hline $\mathrm{PV}_{L}^{t}$ & $0.03 \mathrm{~m}^{3}$ & $0.02 \mathrm{~m}^{3}$ \\
\hline $\mathrm{Pv}_{m}^{t}$ & 3 to $20 \mathrm{~m}^{3}$ & 3 to $20 \mathrm{~m}^{3}$ \\
\hline $\mathrm{bl}_{k}^{t}$ & 20 units & 20 units \\
\hline$\pi_{k L}^{t}$ & 500 Rial & 500 Rial \\
\hline$\delta_{k L}^{t}$ & 100 Rial & 100 Rial \\
\hline W & 10,000 Rial & 10,000 Rial \\
\hline$E X_{L}$ & 52 weeks & 26 weeks \\
\hline$Q_{K L}^{t}$ & 100 units & 100 unit \\
\hline
\end{tabular}




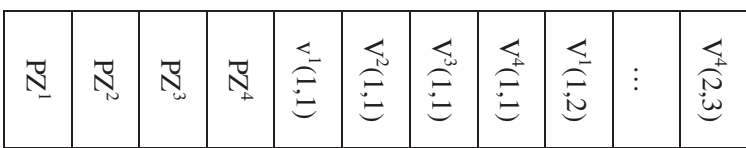

Figure 1 Display of the applied chromosome for coding.

3. The system has been considered for some very significant goods which are highly consumed (at least two highly consumed goods).

4. Demand is fixed and definite in each period.

5. Shortage (lack of inventory) is allowed.

6. Goods that are short-lived have expiration dates (perishable).

7. Expiration date is an integral multiple of the period length.

8. The goods, in some cases, might have been produced before they were ordered by the ordering party, so on their dispatching time, they might have an older manufacturing date than expected.

9. Warehousing system of the original factory (producer) is in the form of FIFO.

10.As the goods' transportation time from the producer factory to other factories is short, the transportation time can be ignored.

11.The producer factory has some limitations for goods maintenance.

12.The customers' demands can be predetermined in each period.

13.The overall capacity of the original producer's warehouse is considered.

\section{Specification and applied indices of the model}

The following are the specifications and applied indices of the model (for more details, see Table 1):
- Total number of customers (factories) $K=1, \ldots, k$

- Total time periods $T=1, \ldots, L$

- Transportation models $M=1, \ldots, m$

\section{Proposed model}

The proposed mathematical model is as follows:

$$
\begin{aligned}
\min z= & \left(\sum_{t} \sum_{m} \sum_{L} \sum_{k} \mathrm{PC}_{K L m}^{t} \cdot X_{K L m}^{t}\right) \\
& +\left(\sum_{t} \mathrm{PF}^{t} \cdot P z^{t}\right)+\left(\sum_{t} \sum_{L} \mathrm{~Pb}_{L}^{t} \cdot\left(\sum_{m} \sum_{k} X_{K L m}^{t}\right)\right) \\
& +\left(\sum_{L} \sum_{t \neq T} \mathrm{dh}_{L}^{t} \cdot \sum_{k}\left(\sum_{m} \sum_{t^{\prime}=1}^{t} X_{K L m}^{t^{\prime}}-\sum_{t^{\prime}}^{t} d_{K L}^{t^{\prime}}\right)\right) \\
& +\left(\sum_{l} \sum_{k} \sum_{t} \delta_{K L}^{t} \cdot B_{K L}^{t}+\sum_{l} \sum_{k} \sum_{t} \pi_{k L}^{t} \cdot \mathrm{In}_{k L}^{t}\right) \\
& +\left(\sum_{t} \sum_{m} \sum_{L} \sum_{k} X_{K L m}^{t}-\sum_{t^{\prime}}^{T} \sum_{k} \sum_{L} d_{K L}^{t^{\prime}}\right) \cdot W
\end{aligned}
$$

\section{Describing the relations}

The first relation is the objective function of the proposed model which includes the total transportation costs of goods from the original factory to the applicant factory, the production cost of goods in the original factory including fixed and variable costs of factory for each production unit, the maintenance costs of inventory in the original factory warehouse, the resulted costs from delayed delivery or earlier delivery of order to the applicant factories, and the resulted costs from perishing the goods in the original factory warehouse.

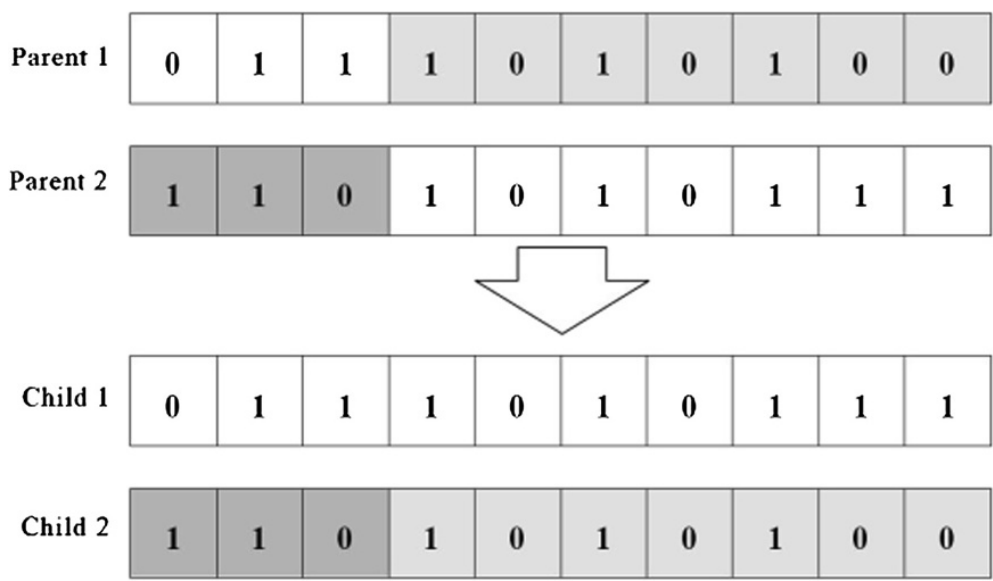

Figure 2 Operation status of crossover operator. 
Table 4 Descending trend of reaching the lowest cost based on 30-time repetition and $\mathbf{3 0}$ chromosomes

\begin{tabular}{lc}
\hline Repetition & Amount function (cost) \\
\hline 1 & $34,450,000$ \\
2 & $34,450,000$ \\
3 & $30,450,000$ \\
4 & $30,450,000$ \\
5 & $30,450,000$ \\
6 & $30,450,000$ \\
7 & $30,450,000$ \\
8 & $30,450,000$ \\
9 & $30,450,000$ \\
10 & $28,450,000$ \\
11 & $28,450,000$ \\
12 & $24,450,000$ \\
13 & $24,450,000$ \\
14 & $22,450,000$ \\
15 & $22,450,000$ \\
16 & $22,450,000$ \\
17 & $22,450,000$ \\
18 & $22,450,000$ \\
19 & $22,450,000$ \\
20 & $20,450,000$ \\
21 & $20,450,000$ \\
22 & $20,450,000$ \\
23 & $20,450,000$ \\
24 & $20,450,000$ \\
25 & $20,450,000$ \\
26 & $20,450,000$ \\
28 & $20,450,000$ \\
30 & $20,450,000$ \\
\hline & $18,450,000$ \\
18 & $18,450,000$ \\
\hline & \\
\hline &
\end{tabular}

\section{Limitations}

The following are the limitations:

Equation 2 shows the related limitation to the factory production time:

$$
\text { St : } \sum_{L} \operatorname{PS}_{L}^{t}\left(\sum_{k} \sum_{m} X_{K L m}^{t}\right) \leq \mathrm{Pu}^{t} \cdot \mathrm{PZ}^{t} \quad \forall_{t}
$$

Equation 3 shows the related limitation to the capacity of original factory warehouses:

$$
\sum_{L} \mathrm{PV}_{L}^{t}\left(\sum_{k} \sum_{m} X_{K L m}^{t}\right) \leq \mathrm{Du}^{t} \cdot \mathrm{PZ}^{t} \quad \forall_{t}
$$

Table 5 The model's suggested times for the main factory activity or non-activity in the $t$ time period

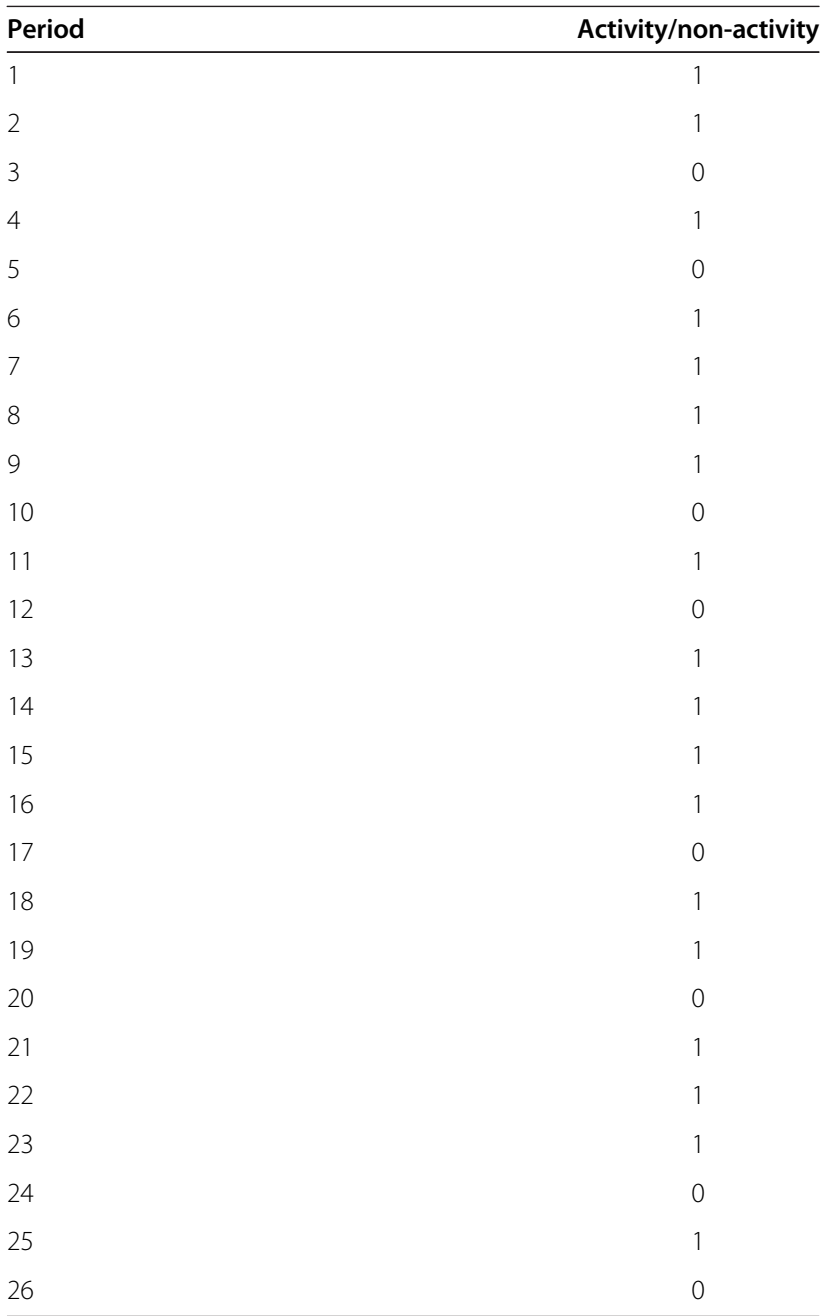

Equation 4 shows the related limitation to the capacity of transportation means in the specified period:

$$
\sum_{k} \sum_{L} \mathrm{PV}_{L}^{t} \cdot X_{K L m}^{t} \leq \mathrm{PV}_{m}^{t} \quad \forall_{t, m}
$$

Equation 5 shows that the limitation specifies the inventory level in the applicants' factories:

$$
\sum_{m} \sum_{t^{\prime}} X_{K L m}^{t^{\prime}}-\operatorname{In}_{k L}^{t}+B_{K L}^{t}=\sum_{t^{\prime}} d_{K L}^{t^{\prime}} \quad \forall_{k, L, t \neq T}
$$

These two limitations (Equations 6 and 7) represent how delay or early delivery will occur in each the planning period:

$$
\operatorname{In}_{k L}^{t} \leq Q_{k L}^{t} \cdot V_{k L}^{t} \quad \forall_{k, L, t}
$$

$$
B_{k L}^{t} \leq b L_{k L}^{t} \cdot\left(1-V_{k L}^{t}\right) \quad \forall_{k, L, t}
$$


Table 6 Maintaining or not maintaining sent goods in the first applying factory $(k 1)$ in the $t$ period

\begin{tabular}{|c|c|c|}
\hline Period & k1 & k2 \\
\hline 1 & 1 & $\overline{1}$ \\
\hline 2 & 1 & 1 \\
\hline 3 & 1 & 1 \\
\hline 4 & 1 & 1 \\
\hline 5 & 0 & 1 \\
\hline 6 & 1 & 1 \\
\hline 7 & 1 & 1 \\
\hline 8 & 0 & 1 \\
\hline 9 & 1 & 1 \\
\hline 10 & 1 & 1 \\
\hline 11 & 1 & 1 \\
\hline 12 & 1 & 1 \\
\hline 13 & 1 & 1 \\
\hline 14 & 1 & 1 \\
\hline 15 & 0 & 1 \\
\hline 16 & 1 & 1 \\
\hline 17 & 1 & 1 \\
\hline 18 & 1 & 1 \\
\hline 19 & 1 & 1 \\
\hline 20 & 1 & 1 \\
\hline 21 & 1 & 1 \\
\hline 22 & 1 & 1 \\
\hline 23 & 1 & 1 \\
\hline 24 & 1 & 1 \\
\hline 25 & 1 & 1 \\
\hline 26 & 1 & 0 \\
\hline
\end{tabular}

This limitation (Equation 8) is related to the factory capacity:

$$
\sum_{m} \sum_{t^{\prime}}^{t} X_{K L m}^{t^{\prime}}-\sum_{t^{\prime}}^{t} d_{K L}^{t^{\prime}} \leq Q_{k L}^{t} \quad \forall_{k, L, t \neq T}
$$

Equation 9 shows the related limitation to perishing the goods:

$$
\begin{aligned}
& \left(\sum_{m} \sum_{t^{\prime}}^{t} X_{K L m}^{t}-\sum_{t^{\prime \prime}=1}^{\min \left(t+E X_{L}, T\right)} d_{K L}^{t^{\prime \prime}}\right)>0 \quad \forall_{k, t \neq T} \\
& \mathrm{PZ}^{t}, V_{k L}^{t}=0 \text { or } 1 \quad \forall_{k, t} \\
& X_{K L m}, \operatorname{In}_{k L}^{t}, B_{k L}^{t} \geq 0 \quad \forall_{k, L, m, t}
\end{aligned}
$$

\section{Case study (Mashhad Behrooz Company)}

Mashhad Behrooz Company is a manufacturing company

\begin{tabular}{|c|c|c|}
\hline Period & k1 & $k 2$ \\
\hline 1 & 1 & 1 \\
\hline 2 & 1 & 1 \\
\hline 3 & 1 & 1 \\
\hline 4 & 1 & 1 \\
\hline 5 & 1 & 1 \\
\hline 6 & 1 & 1 \\
\hline 7 & 0 & 1 \\
\hline 8 & 0 & 1 \\
\hline 9 & 1 & 1 \\
\hline 10 & 0 & 1 \\
\hline 11 & 1 & 1 \\
\hline 12 & 0 & 1 \\
\hline 13 & 0 & 1 \\
\hline 14 & 1 & 1 \\
\hline 15 & 1 & 1 \\
\hline 16 & 1 & 1 \\
\hline 17 & 0 & 1 \\
\hline 18 & 0 & 1 \\
\hline 19 & 1 & 1 \\
\hline 20 & 1 & 1 \\
\hline 21 & 1 & 1 \\
\hline 22 & 1 & 1 \\
\hline 23 & 1 & 1 \\
\hline 24 & 1 & 1 \\
\hline 25 & 1 & 1 \\
\hline 26 & 1 & 1 \\
\hline
\end{tabular}
of all kinds of compotes, conserves, jams, pickles, and
Table 7 Maintaining or not maintaining sent goods in the first applying factory ( $\mathrm{k} 2)$ in the $t$ period

other food products; it has been active in this industry for more than three decades. At present, this company is involved in a supply chain under the brands of Yek \& Yek, Pardis, and Bartar; the variety of goods, limited warehousing space in this company, and short durability of products are major factors which cause some problems in the process of planning and controlling the inventory.

Thus, in view of the above-mentioned issues and with regard to the type of products and their real status, the following values are considered as parameters (Table 2). It should be noted that the proposed model is in a form that the model output also can be evaluated easily by changing indices (for instance, number of customers or number of factories).

Applied indices and their specifications based on the case study

The following are the applied indices and their specifications based on the case study: 
- $K=3$ indicates the number of customers (Golestan Company (k1), Yek \& Yek (k2), Bartar (k3)).

- $L=2$ indicates the number of goods: $\left(L_{1}\right)$ conserved wax bean and $\left(L_{2}\right)$ jam.

- The measurement unit of goods in each carton is 48 pieces.

- $M=4$ indicates the capacities of transportation models (10- to 7-ton truck, trailer, pickup truck).

- $T=52$ indicates the 1-year planning which includes 52 weeks; $t=1$ indicates 1 week, and each week covers six working days.

\section{Ranges of parameters}

Based on the case study, the ranges of parameters are as follows (Table 3):

The daily production capacity of $L_{1}$ is about 40,000 to 100,000 pieces, and the daily production capacity of $L_{2}$ is about 20,000 to 50,000 pieces.

\section{Applied optimization approach using genetic algorithm}

The genetic algorithm was combined with linear programming (LP) and was used in solving the problem of optimization which is a mixed integer linear problem. In this way, the discontinuous variables of the problem are modeled in the genetic algorithm, and in the section of fitness of the genetic algorithm, a LP is recalled.

\section{Coding the problem}

In the genetic algorithm of each generation, there are a few chromosomes (Figure 1) which act as the feasible responses. In order to code the discontinuous variables, the binary alphabet was applied. The discontinuous variables of the problem include $\mathrm{PZ}^{t}$ and $\mathrm{V}_{k l}^{t}$. Thus, the number of bits of a chromosome is equal to

$$
\mathrm{Nb}=T+K \times L \times T .
$$

For example, if the values of these three parameters are supposed as $T=4, K=2$, and $L=3$, we will have

$$
\mathrm{Nb}=4+2 \times 3 \times 4=28
$$

\section{Fitness}

To evaluate the fitness of chromosomes, the value of the proposed objective function is calculated. In such a way that the value of one chromosome in the genetic algorithm is assumed, the values of discontinuous variables of the problem are known. Thus, by replacing these values in the objective function and considering the limitations of the problem, a linear programming problem is formed. By solving this linear problem, the total value of the objective function will be defined and attributed to that chromosome. In this section, if the LP has no feasible response (as this is a minimizing problem), the given chromosome would be penalized with a big value.

\section{Operators of the designed genetic algorithm}

In this problem, selection operator, elitism, crossover operator, mutation operator, and recent reduction operator are determined in such a form that the algorithm

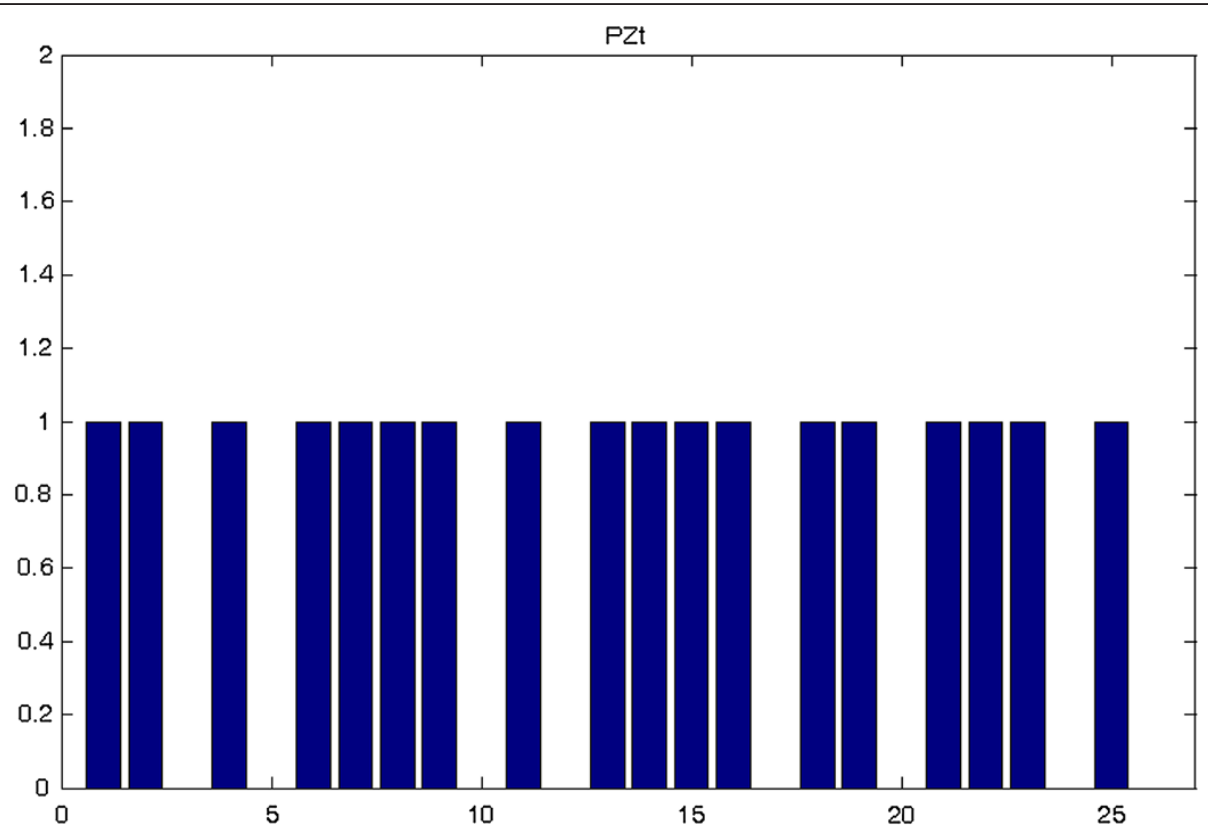

Figure 3 The model's suggested times for main factory activity or non-activity in the $t$ time period. 


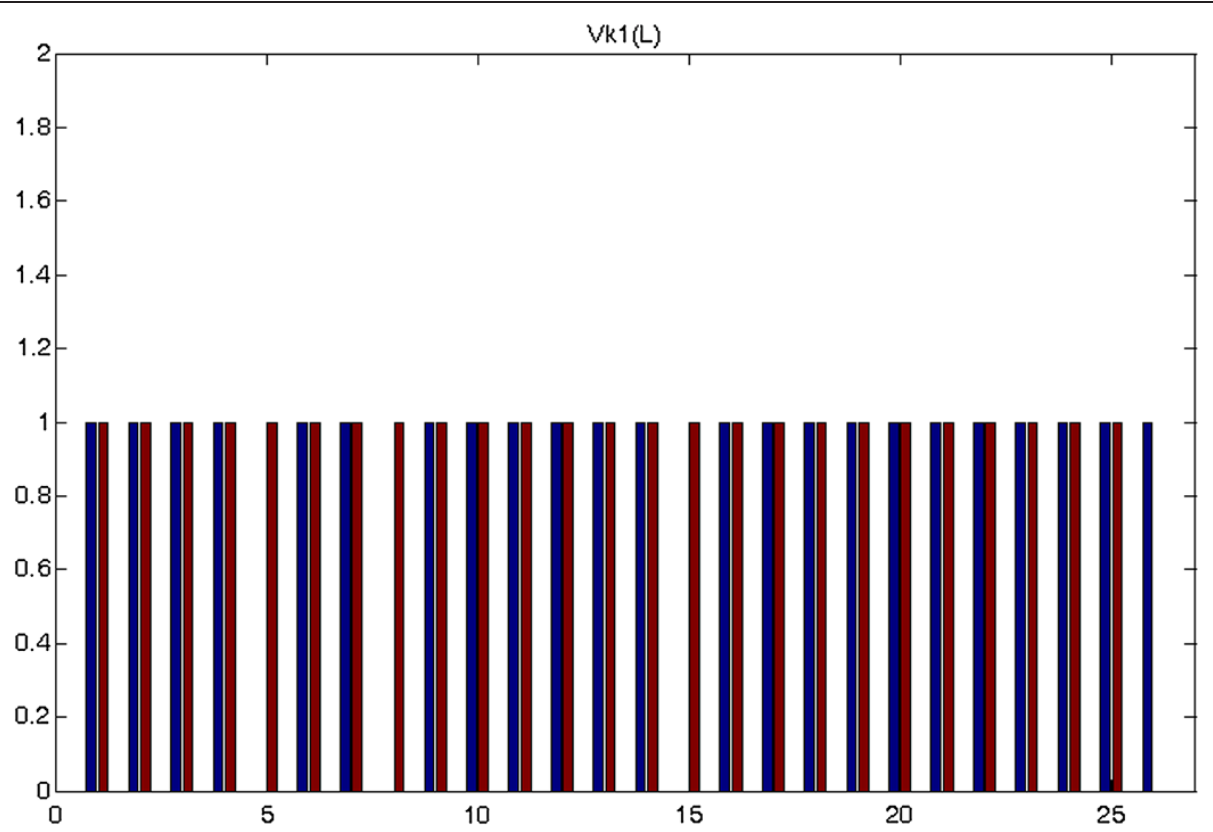

Figure 4 Maintaining or not maintaining sent goods in the first applying factory (k1) in the $t$ period.

reaches a proper result; for example, in a crossover operator (Figure 2), the crossover is done in the form of a single point with the probability of 0.8 .

\section{Sample problems and solving the proposed model}

Now, we solve the problem based on real data in order to analyze the application of the proposed model. A genetic algorithm is designed and proposed using MATLAB software for solving the considered case study. Initially, the program commenced with 15 people for each generation, and there were 30 frequencies for the number of people in each generation, and the frequencies have been increased for the purpose of further research. In addition, this process has been repeated several times

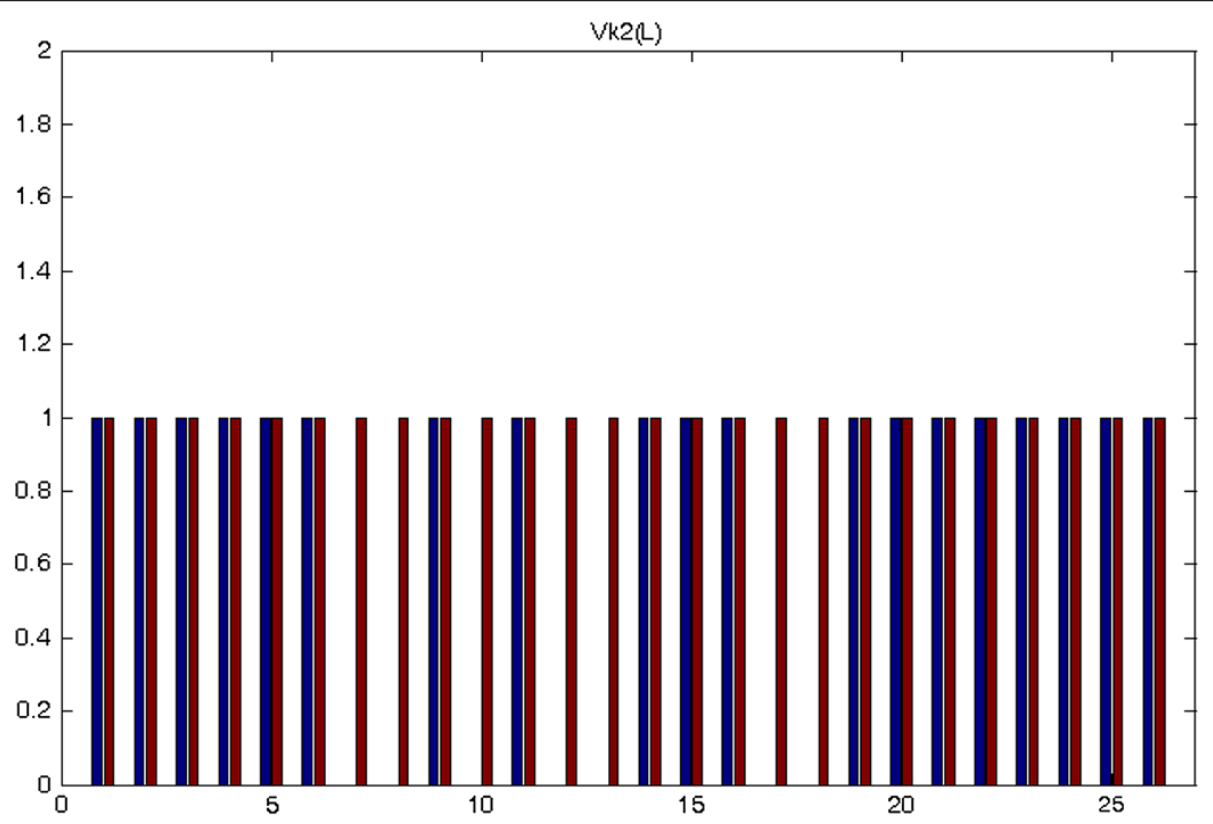

Figure 5 Maintaining or not maintaining sent goods in the first applying factory (k2) in the $t$ period. 
Table 8 Solution and repetition of the presented model considering the change in related parameters

\begin{tabular}{|c|c|c|c|c|c|}
\hline & Repetition & Max-Gen. & Num-pop & $\begin{array}{l}\text { Amount function } \\
\text { (cost) }\end{array}$ & Time \\
\hline 1 & 1 & 30 & 15 & $26,450,000$ & 27 \\
\hline 2 & 2 & 30 & 15 & $26,450,000$ & 26 \\
\hline 3 & 3 & 30 & 15 & $26,450,000$ & 25 \\
\hline 4 & 1 & 40 & 15 & $24,450,000$ & 37 \\
\hline 5 & 2 & 40 & 15 & $24,450,000$ & 36 \\
\hline 6 & 3 & 40 & 15 & $24,450,000$ & 23 \\
\hline 7 & 1 & 50 & 15 & $20,450,000$ & 45 \\
\hline 8 & 2 & 50 & 15 & $20,450,000$ & 45 \\
\hline 9 & 3 & 50 & 15 & $20,450,000$ & 46 \\
\hline 10 & 1 & 30 & 20 & $26,450,000$ & 37 \\
\hline 11 & 2 & 30 & 20 & $2,650,000$ & 33 \\
\hline 12 & 3 & 30 & 20 & $2,650,000$ & 32 \\
\hline 13 & 1 & 40 & 20 & $26,450,000$ & 47 \\
\hline 14 & 2 & 40 & 20 & $26,450,000$ & 45 \\
\hline 15 & 3 & 40 & 20 & $26,450,000$ & 45 \\
\hline 16 & 1 & 50 & 20 & $26,450,000$ & 60 \\
\hline 17 & 2 & 50 & 20 & $26,450,000$ & 59 \\
\hline 18 & 3 & 50 & 20 & $26,450,000$ & 59 \\
\hline 19 & 1 & 30 & 30 & $18,450,000$ & 60 \\
\hline 20 & 2 & 30 & 30 & $18,450,000$ & 64 \\
\hline 21 & 3 & 30 & 30 & $18,450,000$ & 61 \\
\hline 22 & 1 & 40 & 30 & $18,450,000$ & 80 \\
\hline 23 & 2 & 40 & 30 & $18,450,000$ & 81 \\
\hline 24 & 3 & 40 & 30 & $18,450,000$ & 80 \\
\hline 25 & 1 & 50 & 30 & $16,450,000$ & 100 \\
\hline 26 & 2 & 50 & 30 & $16,450,000$ & 100 \\
\hline 27 & 3 & 50 & 30 & $16,450,000$ & 100 \\
\hline 28 & 1 & 70 & 15 & $18,450,000$ & 66 \\
\hline 29 & 2 & 70 & 20 & $24,450,000$ & 86 \\
\hline 30 & 3 & 70 & 30 & $12,450,000$ & 136 \\
\hline 31 & 1 & 100 & 30 & $12,450,000$ & 188 \\
\hline 32 & 2 & 100 & 20 & $24,450,000$ & 122 \\
\hline 33 & 3 & 100 & 15 & $18,450,000$ & 96 \\
\hline 34 & 1 & 150 & 15 & $18,450,000$ & 153 \\
\hline 35 & 1 & 150 & 30 & $12,450,000$ & 138 \\
\hline 36 & 1 & 200 & 30 & $12,450,000$ & 370 \\
\hline
\end{tabular}

with similar numbers to verify its accuracy. The parameter of time was noticed as a part of this problem.

\section{Conclusions}

Based on the obtained results, the following consequences can be referred:
1. By solving the model using genetic algorithm, it is obvious that the operation of the model is quite accurate.

2. Based on testing with real numbers, the practicality of this model can be emphasized.

3. This model was designed for those systems which work in a real setting because in real settings, there may be some goods which are sold late, past their consumption date, and they would not be usable anymore; this model, in addition to minimizing the related costs, minimizes the costs of perishable goods as well.

4. Another output of this model is proposing the time of production, stop, dispatch, and other issues which are completely suitable for real systems.

5. It can be planned easily for a wider range of products by changing the number and specifications of different products.

\section{Suggestions for further research}

The following are suggested for further research:

1. Dependence of sales price on durability of goods in a way that the price of goods will be decreased through passing time from production date of the goods

2. Defining the scrapped price for those goods which are on their due expiry date

3. The possibility of returning those goods which are not confirmed in quality by applicant

4. Defining the neural network as a secondary solution of these models in a way that the output of the genetic algorithm was defined as the input to the neural network; thus, through training, with any change in number of people in each generation and other parameters, in this network, we can find the related response with higher speed

5. Extending the two-echelon model to models with three or more echelons

Table 4 shows two examples to solve the model using a software and using different data in which descending cost trend can be observed.

Of course, other information that were results of solving the model include the amount of goods sent $\left(L_{1}, L_{2}\right)$ by different transportation models (M1, M2, M3, and M4) from the main factory to the applying factories ( $k 1$, $\mathrm{k} 2)$ in the $t$ time period. The total amount of delayed goods $\left(L_{1}, L_{2}\right)$ in applying factories in the $t$ time period, the model's suggested time for the main factory activity or non-activity in the $t$ time period, and maintaining or not maintaining the sent goods in applying factories $(\mathrm{k} 1$, $\mathrm{k} 2$ ) in the $t$ time period are shown in Tables 5,6 , and 7 and Figures 3, 4, and 5, wherein we show two recent 
examples based on 30 chromosomes and 30-time repetitions.

Finally, the Table 8 is the overall result in solving the model using the software, and different data for several repetitions.

As we can see, with this number of experiments, the best obtained result is the amount 12,450,000 which is shown in rows $35,31,30$, and 36 of Table 8 . Thus, considering the obtained result, we do not continue the solving process.

\section{Competing interests}

The authors declare that they have no competing interests.

\section{Authors' contributions}

Late Dr. MGA was a distinguished full professor of Industrial Engineering in Iran. He was an excellent expert in the field of operational research and modeling. Dr. AM, Associate Professor of school of Industrial Engineering at University of Science and Technology, Tehran, Iran. An expert in the field of research, production planning, Supply chain, Decision making and modeling techniques. SK, assistant professor of Dep. of management at Islamic Azad University. Mashhad Branch, most of his time is devoted to and occupied by doing research on the field of production planning and inventory control.

\section{Acknowledgements}

authors are grateful to the editor of Journal of Industrial Engineering International as well the anonymous referees for valuable and constructive comments to enhance quality of the paper.

\section{Author details}

'Dep. Of Industrial Management, Science and Research Branch, Islamic Azad University, Tehran, Iran. ${ }^{2}$ Dep. Of Industrial Engineering, University of Science and Technology, Tehran, Iran. ${ }^{3}$ Dep. Of Management, Mashhad Branch, Islamic Azad University, Mashhad, Iran.

Received: 2 October 2012 Accepted: 19 October 2013

Published: 30 Dec 2013

\section{References}

Bertrand IP, Bookbinder JH (1998) Stock redistribution in two-echelon logistic systems. J Oper Res Soc 49(9):966-975

Bollapragada S, Akella R, Srinivasan R (1998) Centralized ordering and allocation policies in a two-echelon system with non-identical warehouses. Eur J Oper Res 106:74-81

Bookbinder JH, Chen VYX (1992) Multi criteria trade-offs in a warehouse-retailer system. J Oper Res Soc 43(7):707-720

Chen C, Lee W (2004) Multi-objective optimization of multi-echelon supply chain networks with uncertain product demands and prices. Comput Chem Eng 28:1131-1144

Dada M (1992) A two-echelon inventory system with priority shipments. Manag Sci 38(8):1140-1153

Dai T, Qi X (2007) An acquisition policy for a multi-supplier system with a finite-time horizon. Comp Oper Res 34(9):2758-2773

Erenguc SS, Simpson NC, Vakharia AL (1999) Integrated production /distribution in supply chain, an invited review. Euro J Oper Res 115:219-236

Hoque MA, Goyal SK (2000) An optimal policy for a single-vendor single-buyer integrated production-inventory system with capacity constraint of the transport equipment. Int J Prod Econ 65:305-315

Hwang HS (2002) Design of supply chain logistics system considering service level. Comput Ind Eng 43:283-297

Kyung PS, Dae KH (1989) Stochastic inventory model for two-echelon distribution system. Comp Ind Eng 16(2):245-255

Miner S (2005) Multiple-Supplier inventory models in supply chain management a review. Int J Prod Eco

Moon, et al. (2005) Economic order quantity models for ameliorating /deteriorating items under inflation and tied discounting. Eur J Oper Res 162:773-785
Rau HMY, Wu H, Wee M (2003) Integrated inventory model for determining items under a multi-echelon supply chain environment. Int J Prod Eco 86:155-168

Shtub A, Simon M (1994) Determination of reorder points for spare parts in a two-echelon inventory system: the case of non-identical maintenance facilities. Eur J Oper Res 73(3):458-464

Wang W, Fung RYK, Chai Y (2003) Approach of just-in-time distribution requirements planning for supply chain management. Int J Prod Econ 91:101-107

Yang PC, Wee HM (2002) A Single vendor and multiple buyers production inventory policy for a deteriorating item. Eur J Oper Res 145:570-581

Zhou G, Min H (2002) The balanced allocation of customers to multiple distribution centers in the supply chain network: a genetic algorithm approach. Comput Ind Eng 43:251-261

10.1186/2251-712X-9-39

Cite this article as: AriaNezhad et al:: Developing and solving two-echelon inventory system for perishable items in a supply chain: case study (Mashhad Behrouz Company). Journal of Industrial Engineering International 2013, 9:39

\section{Submit your manuscript to a SpringerOpen ${ }^{\circ}$ journal and benefit from:}

- Convenient online submission

- Rigorous peer review

- Immediate publication on acceptance

- Open access: articles freely available online

- High visibility within the field

- Retaining the copyright to your article

Submit your next manuscript at $>$ springeropen.com 